\title{
ARTICLE
}

Myelodysplastic syndrome

\section{Impact of somatic mutations in myelodysplastic patients with isolated partial or total loss of chromosome 7}

\author{
Elena Crisà $\mathbb{D}^{1,2,3} \cdot$ Austin G. Kulasekararaj ${ }^{1} \cdot$ Vera Adema $^{4,5} \cdot$ Esperanza Such $^{6,7} \cdot$ Julie Schanz $^{8} \cdot$ Detlef Haase $^{8}$. \\ Katayoon Shirneshan ${ }^{8}$. Steven Best ${ }^{9} \cdot$ Syed A Mian ${ }^{1,10}$ - Aytug Kizilors ${ }^{9}$ - José Cervera ${ }^{11}$ - Nicholas Lea ${ }^{9}$. \\ Dario Ferrero $^{3,12}$. Ulrich Germing ${ }^{13}$ - Barbara Hildebrandt ${ }^{14}$. Ana Belén Valencia Martínez ${ }^{15}$ - Valeria Santini ${ }^{3,15}$. \\ Guillermo F. Sanz $\mathbb{1}^{6,7,16} \cdot$ Francesc Solé ${ }^{4} \cdot$ Ghulam J. Mufti ${ }^{1}$
}

Received: 23 July 2019 / Revised: 19 December 2019 / Accepted: 28 January 2020 / Published online: 17 February 2020

(c) The Author(s), under exclusive licence to Springer Nature Limited 2020

\begin{abstract}
Monosomy 7 [-7] and/or partial loss of chromosome 7 [del(7q)] are associated with poor and intermediate prognosis, respectively, in myelodysplastic syndromes (MDS), but somatic mutations may also play a key complementary role. We analyzed the impact on the outcomes of deep targeted mutational screening in 280 MDS patients with $-7 / \mathrm{del}(7 \mathrm{q})$ as isolated cytogenetic abnormality (86 with del(7q) and 194 with -7 ). Patients with del(7q) or -7 had similar demographic and diseaserelated characteristics. Somatic mutations were detected in $79 \%(93 / 117)$ of patients (82\% in -7 and $73 \%$ in del(7q) group). Median number of mutations per patient was 2 (range 0-8). There was no difference in mutation frequency between the two groups. Patients harbouring $\geq 2$ mutations had a worse outcome than patients with $<2$ or no mutations (leukaemic transformation at 24 months, $38 \%$ and $20 \%$, respectively, $p=0.044)$. Untreated patients with del( $7 q)$ had better overall survival (OS) compared with -7 (median OS, 34 vs 17 months, $p=0.034$ ). In multivariable analysis, blast count, TP53 mutations and number of mutations were independent predictors of OS, whereas the cytogenetic subgroups did not retain prognostic relevance. This study highlights the importance of mutational analysis in terms of prognosis in MDS patients with isolated -7 or del(7q).
\end{abstract}

\section{Introduction}

Recurrent chromosomal abnormalities occur in 50\% of patients with myelodysplastic syndrome (MDS), and the type and complexity of the aberrations correlate with transformation into acute myeloid leukaemia (AML) and overall survival (OS). Notably, isolated monosomy $7(-7)$ and/or partial loss of the long arm of chromosome 7 (del 7q) and $-7 / \operatorname{del}(7 \mathrm{q})$ with additional cytogenetic aberration(s) are the second most frequent chromosomal abnormalities in MDS, and are associated with a poor OS and high transformation rate to AML [1-5].

The most commonly used prognostic tools for evaluating patients with MDS are the International Prognostic Scoring

Supplementary information The online version of this article (https:// doi.org/10.1038/s41375-020-0728-x) contains supplementary material, which is available to authorised users.

Elena Crisà

elena.crisa@med.uniupo.it

Extended author information available on the last page of the article
System (IPSS) [6] and its revised version, the IPPS-R. In the IPSS, chromosome 7 abnormalities were grouped into the poor-risk chromosomal risk category. Given the demonstration that isolated $\operatorname{del}(7 q)$ and -7 have a different impact on outcomes [7-10], these two different chromosome 7 abnormalities were segregated into different risk categories in the IPSS-R $[8,11]$.

Median OS for patients with isolated $\operatorname{del}(7 \mathrm{q})$ is between 20 and 40 months as compared with 9 and 20 months for isolated -7 [7-10] (Supplementary data Table 1). However, these studies included only untreated patients and were limited by a small patient number; only 59 patients had isolated abnormalities of chromosome 7 in the international database on which IPSS-R was based [8].

There are three common deleted regions on $7 \mathrm{q}$. These include band 7q22 (the most frequent) and the more telomeric regions 7q31-32 and 7q36 [12-14], but they do not seem to impact prognosis in a study by using SNP-A karyotyping [10]. The role of chromosome 7 abnormalities in the pathogenesis of MDS is not yet well characterised. It has been proposed that either mutations (EZH2 [15-17]) or specific gene haploinsufficiency $[14,18-22]$, or an 
epigenetic mechanism of silencing of genes located in the $7 q$-deleted region could play a role [10]. However, unlike MDS with del(5q), a clear correlation between genotype and phenotype has not been demonstrated for chromosome 7 aberrations [23]. Moreover, if the partial and the complete loss of chromosome 7 are sequential stepwise events, the route to these abnormalities, and why these two different defects of the same chromosome have a different impact on prognosis, are still unclear.

The relationship between somatic gene mutations and single chromosome 7 abnormalities, and the impact of the former on the outcomes of this specific MDS patient population, are unknown.

The purpose of this study was to describe the clinical features, bone marrow (BM) characteristics and myeloidrelated somatic gene mutations in a large and wellcharacterized cohort of MDS and MDS/myeloproliferative neoplasm (MPN) patients with isolated abnormalities involving chromosome 7 . In particular, we aimed to assess the independent prognostic relevance for the outcomes of somatic gene mutations in patients with either single -7 or $\operatorname{del}(7 q)$ chromosomal abnormalities.

\section{Methods}

\section{Patients}

We evaluated 280 patients with $\operatorname{MDS}(N=245)$ or MDS/ MPN $(N=35)$ who had either at diagnosis $(N=267)$ or developed during follow-up $(N=13)$ a total or partial loss of chromosome 7 as an isolated chromosomal abnormality. The diagnosis was carried out on the basis of the World Health Organization (WHO) classification 2008 [24]. We excluded all patients with either complex or double abnormalities that included -7 or $\operatorname{del}(7 q)$.

Patients included in the study were referred by King's College Hospital NHS Trust, the Spanish MDS group (GESMD), University Medical Center Göttingen, University Hospital Düsseldorf, the University of Turin and the MDS Unit, AOUC, University of Florence. Informed consent was obtained following the Declaration of Helsinki, according to protocols approved by the review boards and ethics committees of the participating institutions. Patients and disease characteristics (age, sex, haemoglobin levels, platelet counts, absolute granulocyte counts, percentage of blasts in BM, BM cellularity and fibrosis (age-adjusted BM cellularity and fibrosis were assessed on BM trephine, according to European consensus [25, 26]), duration of disease and de novo, secondary or therapy-related MDS), transfusion dependency at diagnosis (defined according to IWG 2006 criteria [27]), IPSS and IPSS-R prognostic scores, administered therapies and previous diagnosis of aplastic anaemia or other BM failure syndromes were collected and included in the prognostic factor analyses.

Family history and clinical signs of familial disease were checked and recorded in all the patients, particularly in the younger ones. Patients in whom a disease with genetic predisposition to MDS or inherited BM failure was diagnosed were excluded from this study.

The patients previously diagnosed with aplastic anaemia were also screened to rule out Fanconi anaemia (by chromosomal breakage analysis), Shwachman-Diamond syndrome and some common telomere biology diseases (by mutational analysis of the genes TERC, TERT and TINF2).

Patients who acquired -7 or $\operatorname{del}(7 q)$ over follow-up were characterized from the time of the cytogenetic abnormality detection.

\section{Next-generation sequencing (NGS) analysis}

BM samples at diagnosis or at the stage of first $-7 / \operatorname{del}(7 \mathrm{q})$ detection were available for 117 of 280 patients; 84 of them carried -7 and 33 del(7q). DNA extraction from BM total nucleated cells was performed by using QIAamp DNA extraction kit (Qiagen), according to the manufacturer's protocol. Gene mutation screening for commonly mutated myeloid-related genes was performed by using King's College Hospital myeloid-gene panel. PCR amplification of the coding regions or known hotspots of genes including ASXL1, BCOR, CBL, CEBPA, DNMT3A, ETV6, EZH2, FLT3, GATA2, IDH1, IDH2, JAK2, KDM6A, KIT, KRAS, NPM1, NRAS, RUNX1, SF3B1, SRSF2, STAG2, TET2, TP53, U2AF1 and ZRSR2 was performed as described previously [28] (Supplementary Table 2). This method was designed to detect somatic nucleotide variants and small insertions/deletions $(<50 \mathrm{bp})$ within the coding regions of the targeted genes. Sequencing was performed using the MiSeq Instrument with version -2 or -3 sequencing chemistry (Illumina, San Diego, CA, USA), as per the manufacturer's instructions. Sequencing data were processed using the GATK pipeline package (Broad Institute, Boston, MA, USA). Processed VCF and BAM files were visualised using variant studio (Illumina) and integrated genome viewer, respectively. Variants were excluded if the Q score was less than 30, total read depth $<200$, variant allele frequency (VAF) $<5 \%$ and presence of strand bias, present in 5'UTR, 3'UTR, noncoding RNA, intronic region were synonymous. Deletions and duplications were included. Unreported variants were excluded if outside the hotspot in 'hotspot genes'. All variants with a population allele frequency of $>1 \%$ described in dbSNP132, ESP5400 and 1000 genomes project were considered as common SNPs and were also excluded. The variants were assessed in context with their somatic status and frequency in published cancer databases-COSMIC (Catalogue of Somatic 
Mutations in Cancer), ClinVar, The Cancer Genome Atlas database and large published studies on the genomic landscape of AML and MDS. VAF for EZH2 was analyzed without correction for loss of heterozygosity.

\section{Statistical methods}

Demographic and clinical covariates were compared using the Kruskal-Wallis test for continuous variables and Pearson's chi-square test for categorical variables. OS was estimated by using the Kaplan-Meier method, and any statistical difference between curves was assessed by using log-rank tests. OS was defined as the time elapsed between diagnosis and death or the last follow-up. To analyze the impact of therapeutic choice and mutations on survival, patients who underwent allogeneic haematopoietic cell transplantation (allo-HCT) were censored at the time of transplantation. In survival analysis that included allo-HCT as a variable, we censored patients at death or the last follow-up. AML-free survival was defined as the time elapsed from diagnosis to AML diagnosis. AML cumulative incidence risk was calculated by the cumulative function with death without AML progression considered as a competing event.

Cox proportional hazards models were used to compare the different risk factors by the Wald test: gender, age at diagnosis ( $>65$ vs $\leq 65$ years), isolated -7 vs $\operatorname{del}(7 q$ ), diagnosis (according to $\mathrm{WHO}$ ), primary vs therapy-related disease, BM blasts (categorised as $<5 \%, 5-10 \%$ and 11-19\%), BM cellularity (hypocellular, normocellular and hypercellular), first-line therapy, allo-HCT and gene somatic mutations.

Multivariate analysis using the Cox proportional hazards regression method for temporal events was used to identify the most significant independent prognostic variables for OS and AML transformation. The characteristics selected for possible inclusion in the multivariate model were those for which there was some indication of a significant association with OS or AML transformation in the univariate analysis. Only cases with complete data for all variables were included in the regression procedure.

All reported $P$ values were two sided, and the conventional 5\% significance level was used for defining statistically significant differences. Data were analyzed as of February 2019 by SPSS 20.0 .0 and R package.

\section{Results}

\section{Patients' characteristics}

We included 280 patients, 194 with -7 and 86 with del(7q). Median follow-up was 26 months (range 1-182 months).
Median age at diagnosis was 65 years (range 16-88 years). Patients with -7 had a lower platelet count at presentation, and were at higher IPSS-R risk than patients with $\operatorname{del}(7 \mathrm{q})$, $p<0.001$ and $p<0.001$, respectively. No other statistically significant difference in demographic, patient and disease characteristics was observed between the two groups (Table 1). Of note, the percentage of patients with hypocellular marrow (26\%) was slightly higher than expected in an MDS population (10-20\%) [29, 30].

Moreover, patients with hypocellular marrow were slightly younger than the others, as median age was 61 years in the hypocellular group, 64 in the normocellular group and 66 in the hypercellular group. However, the age distribution was not statistically different in the three groups $(\mathrm{p}=0.671)$.

Interestingly, 12 patients were previously diagnosed with aplastic anaemia, and 11 out of 12 had -7 at transformation to MDS, whereas only one presented with del(7q).

In all those 12 patients, other congenital BM failure diseases were excluded, as previously described in this section 'Methods'.

There was no significant correlation between cellularity and previous aplastic anaemia (at the MDS stage, three patients with aplastic anaemia had a normocellular marrow, three hypercellular marrow and six hypocellular marrow, $\mathrm{p}=0.170)$.

\section{Treatment}

Data on treatment were available for 266 patients, and no significant differences were noted in the treatments received between the cytogenetic subgroups.

Overall, 139 of 266 (52\%) patients were treated. Out of $139(21 \%)$ patients, 29 received intensive chemotherapy (IC) as first-line treatment (an induction course followed by one to two consolidation courses with either fludarabine + cytarabine + idarubicin, or cytarabine + idarubicin + etoposide, or standard ' $3+7$ ' with daunorubicin or idarubicin), 80 (58\%) azacitidine (AZA) for a median of six courses (range 1-19), 12 (9\%) immunosuppressive drugs (including cyclosporine and steroids), 10 (7\%) allo-HCT and $8(6 \%)$ other therapies (including hydroxycarbamide, thalidomide, lenalidomide and low-dose cytarabine). Fiftyfive patients (21\%) underwent allo-HCT: 22 after receiving IC, 13 after AZA, 8 after AZA and IC, 2 after immunosuppressive treatment and 10 upfront.

Patients receiving IC were younger than patients treated with AZA, median age 49 vs 71 , respectively, $p<0.001$.

\section{Mutational data}

Somatic mutations were found in $79.5 \%$ (93/117) of patients; $82 \%(69 / 89)$ in -7 and $73 \%$ (24/33) in $\operatorname{del}(7 q)$ 
Table 1 Patient characteristics at diagnosis.

\begin{tabular}{|c|c|c|c|c|}
\hline & $\begin{array}{l}\text { All patients } \\
\text { No }(\%)\end{array}$ & $\begin{array}{l}-7 \\
\text { No }(\%)\end{array}$ & $\begin{array}{l}\operatorname{del}(7 q) \\
\text { No }(\%)\end{array}$ & $P$ value \\
\hline Gender & & & & 0.482 \\
\hline Male & $181(65)$ & $128(66)$ & $53(62)$ & \\
\hline Female & $99(35)$ & $66(34)$ & $34(38)$ & \\
\hline $\begin{array}{l}\text { Median age at diagnosis } \\
\text { (range) }\end{array}$ & $65(16-88)$ & $64(16-88)$ & $65(16-88)$ & 0.554 \\
\hline$<30$ years & $18(6)$ & $14(7)$ & $4(5)$ & \\
\hline $30-49$ years & 37 (13) & $27(14)$ & $10(12)$ & \\
\hline 50-64 years & $84(31)$ & $56(29)$ & $28(32)$ & \\
\hline $65-79$ years & $110(39)$ & $79(41)$ & $31(36)$ & \\
\hline$>80$ years & $31(11)$ & $18(9)$ & $13(15)$ & \\
\hline WHO subtype & & & 0.811 & \\
\hline RA & $20(7)$ & $11(6)$ & $9(11)$ & \\
\hline RARS & $10(4)$ & $7(4)$ & $3(3)$ & \\
\hline RCMD & $90(32)$ & $61(31)$ & $29(34)$ & \\
\hline RAEB1 & $51(18)$ & $37(19)$ & $14(16)$ & \\
\hline RAEB2 & $63(21)$ & $44(23)$ & $20(23)$ & \\
\hline MDS-U & $10(4)$ & $7(4)$ & $3(3)$ & \\
\hline CMML & $29(10)$ & $22(10)$ & $7(8)$ & \\
\hline MDS/MPN & $6(2)$ & $5(3)$ & $1(1)$ & \\
\hline Therapy-related disease & $32(12)$ & $23(12)$ & $9(10)$ & 0.640 \\
\hline Cellularity & & & & 0.738 \\
\hline Normocellular & $56(32)$ & $39(31)$ & $17(35)$ & \\
\hline Hypocellular & $46(26)$ & $32(26)$ & $14(29)$ & \\
\hline Hypercellular & $72(41)$ & $54(43)$ & $18(37)$ & \\
\hline Transfusion dependency & & 0.498 & & \\
\hline Yes & $87(40)$ & $58(38)$ & $29(43)$ & \\
\hline No & $131(60)$ & $93(62)$ & $38(57)$ & \\
\hline IPSS & & & & 0.396 \\
\hline Intermediate 1 & $42(18)$ & $25(15)$ & $17(23)$ & \\
\hline Intermediate2 & $130(55)$ & $91(56)$ & $39(52)$ & \\
\hline High & $65(27)$ & $46(28)$ & $19(25)$ & \\
\hline IPSS-R & & & & $<0.001$ \\
\hline Low & $27(13)$ & $11(8)$ & $16(27)$ & \\
\hline Intermediate & $52(26)$ & $34(24)$ & $18(30)$ & \\
\hline High & $61(30)$ & $43(30)$ & $18(30)$ & \\
\hline Very high & $61(30)$ & $53(38)$ & $8(13)$ & \\
\hline $\mathrm{ANC}\left(\mathrm{x} 10^{9} / \mathrm{L}\right)$ & $1.36(0.0-48.4)$ & $1.33(0.0-48.4)$ & $1.30(0.1-12.4)$ & 0.753 \\
\hline $\mathrm{HB}(\mathrm{g} / \mathrm{dL})$ & $10(3.0-16.0)$ & $10(3.0-15.0)$ & $10(5-16.0)$ & 0.161 \\
\hline $\operatorname{PLTS}\left(\times 10^{9} / \mathrm{L}\right)$ & $88(3-794)$ & $83(3-597)$ & $122(8-794)$ & $<0.001$ \\
\hline
\end{tabular}

group $(p=0.256)$. Median number of mutations per patient was 2 (range $0-8$ ) with 54 and $49 \%$ of -7 and $\operatorname{del}(7 q$ ) patients harbouring $\geq 2$ mutations, respectively $(P=0.521)$. VAF of all genes according to -7 or $\operatorname{del}(7 q)$ is shown in Fig. 1. There was no difference in mutation distribution or VAF between the two groups (Figs. 1 and 2).

Overall, 54\% of patients had mutations in genes involved in epigenetic and chromatin modifications, $30 \%$ in splicing factors, $20 \%$ in cell signalling and $33 \%$ in transcription factors (Fig. 3). U2AF1 mutations were associated with lower haemoglobin level $(8 \mathrm{~g} / \mathrm{dL}$ vs $10,2 \mathrm{~g} / \mathrm{dL}, P<0.001$ and platelets $84 \times 10^{9} / \mathrm{L}$ vs $123 \times 10^{9} / \mathrm{L}, P 0.046$ ), whereas patients with TET2 mutation had higher WBC count $\left(10.6 \times 10^{9} / \mathrm{L}\right.$ vs $\left.3.2 \times 10^{9} / \mathrm{L}, P=0.018\right)$. Patients who harboured $\geq 1$ mutation were older (median age, 54, 65 and 67 years in patients with 0,1 and 2 or more mutations, respectively; $P=0.046$ ). In particular, TET2 and TP53 mutations were associated with older age compared with patients without mutations $(P=0.010$ and 0.008 , respectively).

In this cohort of patients, the percentage of mutations in genes involved in methylation and chromatin modification (in particular ASXL1, DNMT3A and EZH2), and in other genes known to have an adverse prognostic impact [31,32] (i.e. RUNX1, U2AF1, NRAS and ETV6), was higher than previously described $[31,33,34]$ in MDS patients. On the contrary, we observed fewer patients with TET2, SF3B1, SRSF2 and STAG2 mutations (Fig. 2).

Of the eight patients with a previous history of aplastic anaemia, in whom samples were available, mutations were detected in $62 \%$ of them, and only three patients had $\geq 2$ mutation (range 1-5). The most frequently mutated gene was ASXL1 (mutated in four patients), followed by EZH2 and $R U N X 1$ (two patients, respectively) and $U 2 A F 1, S F 3 B 1$ and $C B L$ in one patient each. No mutations in $B C O R$ were found in this cohort.

\section{Overall survival and response to treatment}

In this large series, OS for del(7q) patients was longer compared with -7 patients, but this difference was not statistically significant (median OS 34 months vs 27 months, respectively; $P=0.268$ ) (Fig. 4b). However, as expected, there was a statistically significant difference in OS between the two cytogenetic groups in untreated patients $(n=127)$ and favouring del(7q) cases (median OS 34 vs 17 months, $P=0.034$ (Fig. 4a)).

Of note, there was no difference in response rates to AZA or IC or immunosuppressive drugs in patients with del (7q) or -7 (data available for 92 patients only) (Supplementary data Table 3).

There was no difference in OS between patients treated with IC or AZA front line (median OS 35 vs 28 months, $p=0.297$ ). However, patients who underwent allo-HCT had a longer OS (median 35 vs 26 months, $P=0.003$ ), regardless of the allo-HCT pre-treatment. Of note, median age of transplanted patients was 50 years, and $62 \%$ were $<60$ years old.

The 12 patients previously diagnosed with aplastic anaemia had a similar outcome as compared with de novo MDS (median OS censored at allo-HCT, 32 vs 28 months, $P=0.678$ ), even if the long-term outcome was better as 9 out of 12 underwent allo-HCT. In particular, in this small subset of patients, there was no difference in OS and AML cumulative incidence risk according to the presence of mutations.

We also performed all the survival analysis without the 12 patients who developed MDS after a diagnosis of aplastic anaemia and there was no change in patients' outcome (detailed analysis in Supplementary data, including multivariable analysis in Table 4). 


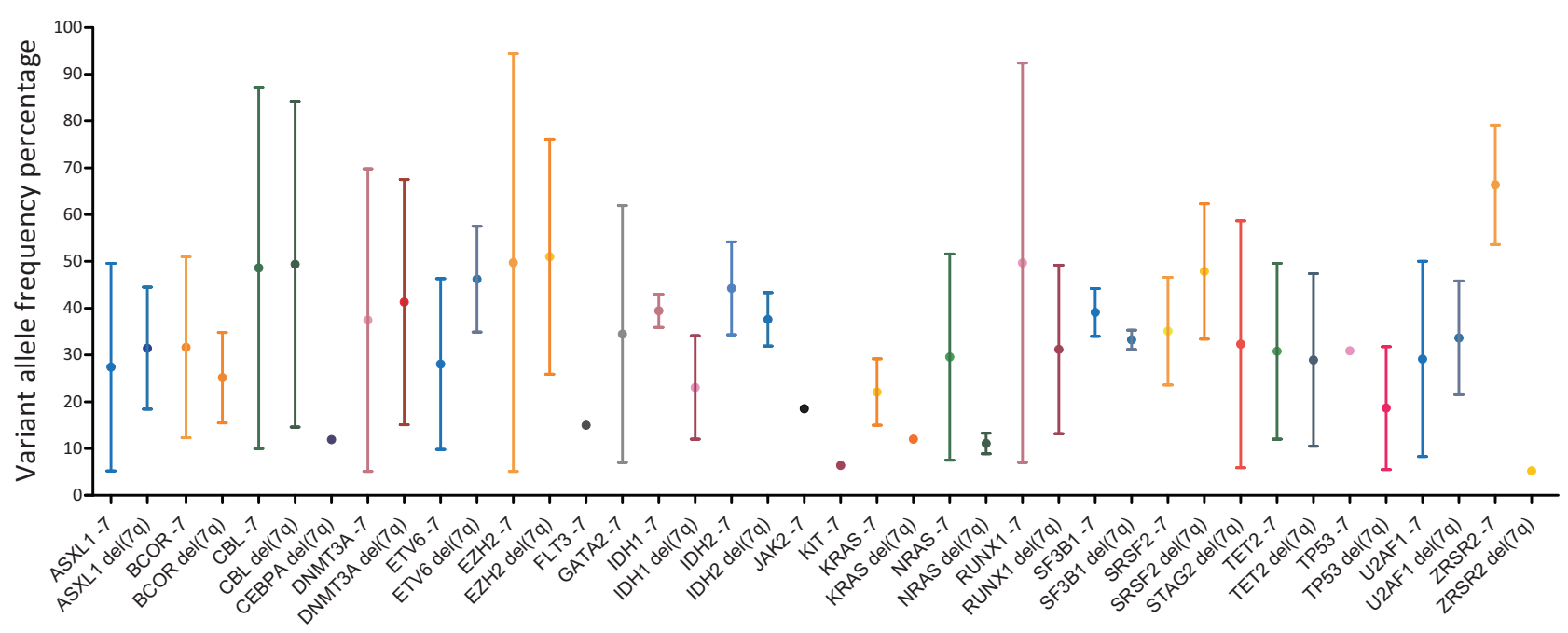

Fig. 1 Variant allele frequency (VAF) of all genes according to -7 or $\operatorname{del}(7 q)$.

Fig. 2 Mutation distribution across $\operatorname{del}(7 q)$ and -7 patients.

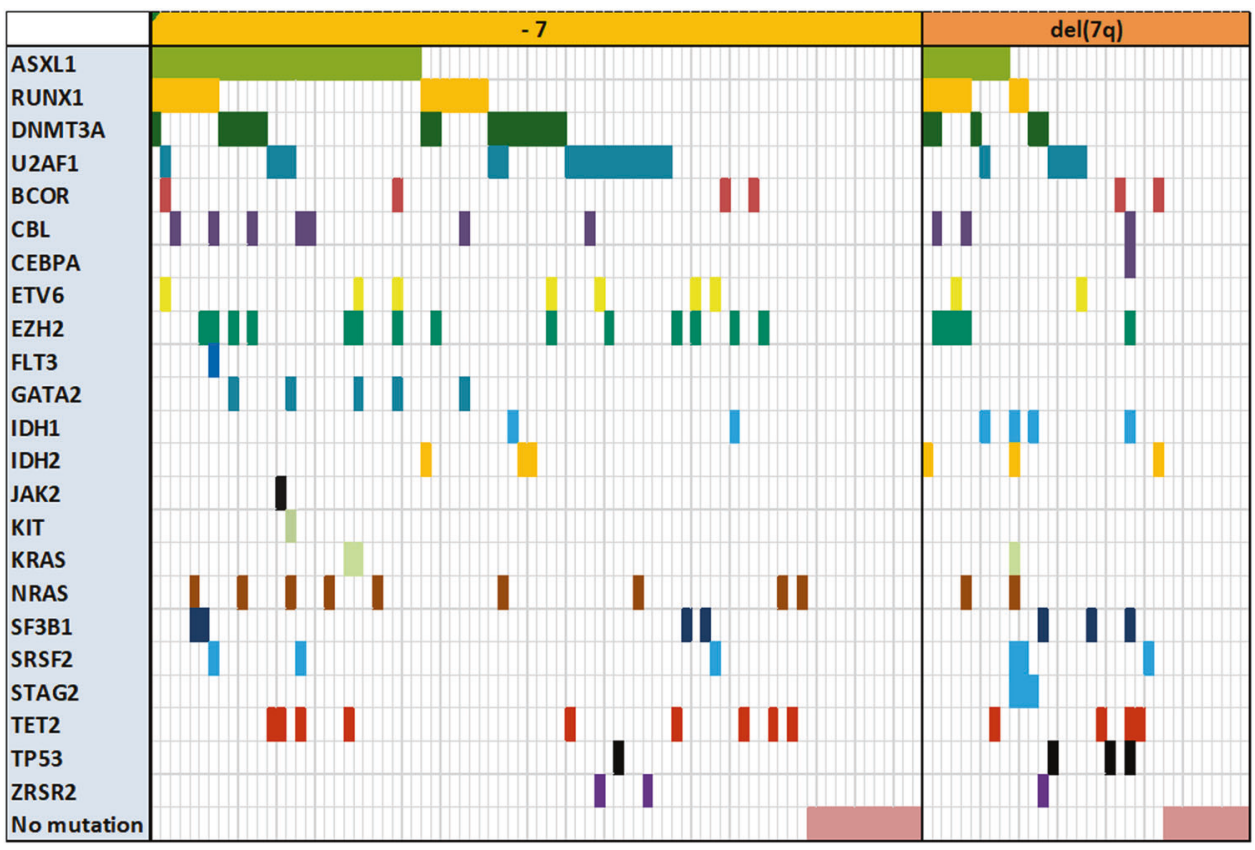

\section{Impact of somatic mutations on survival and response to therapy}

In univariable analysis, patients who harboured $\geq 2$ mutations of any of the genes in the panel had a worse outcome than patients without any mutation $(P=0.035)$ or with only one mutation $(P=0.016)$ (Fig. 5), regardless of the cytogenetic group. TP53 mutations were confirmed as a strong predictor of poor outcome, regardless of the small number of patients with mutations $(P<0.001)$, together with mutations in splicing factors $(P=0.014)$ and in NRAS $(P=0.017)$. By contrast, patients with
$B C O R$ mutations had a longer survival than wild-type patients $(P=0.050)$.

Mutations in splicing factors were associated with a worse outcome when considered altogether, including SF3B1. However, by taking the splicing factor genes individually, none of them impacted significantly on OS, even if U2AF1 and SRSF2 had a trend towards shorter survival, and SF3B1 towards longer survival (of note, only seven patients carried a mutation in $S F 3 B 1$, of whom only three as isolated mutation). We also performed the survival analysis without SF3BI in the splicing factor genes, and the association between splicing factor 


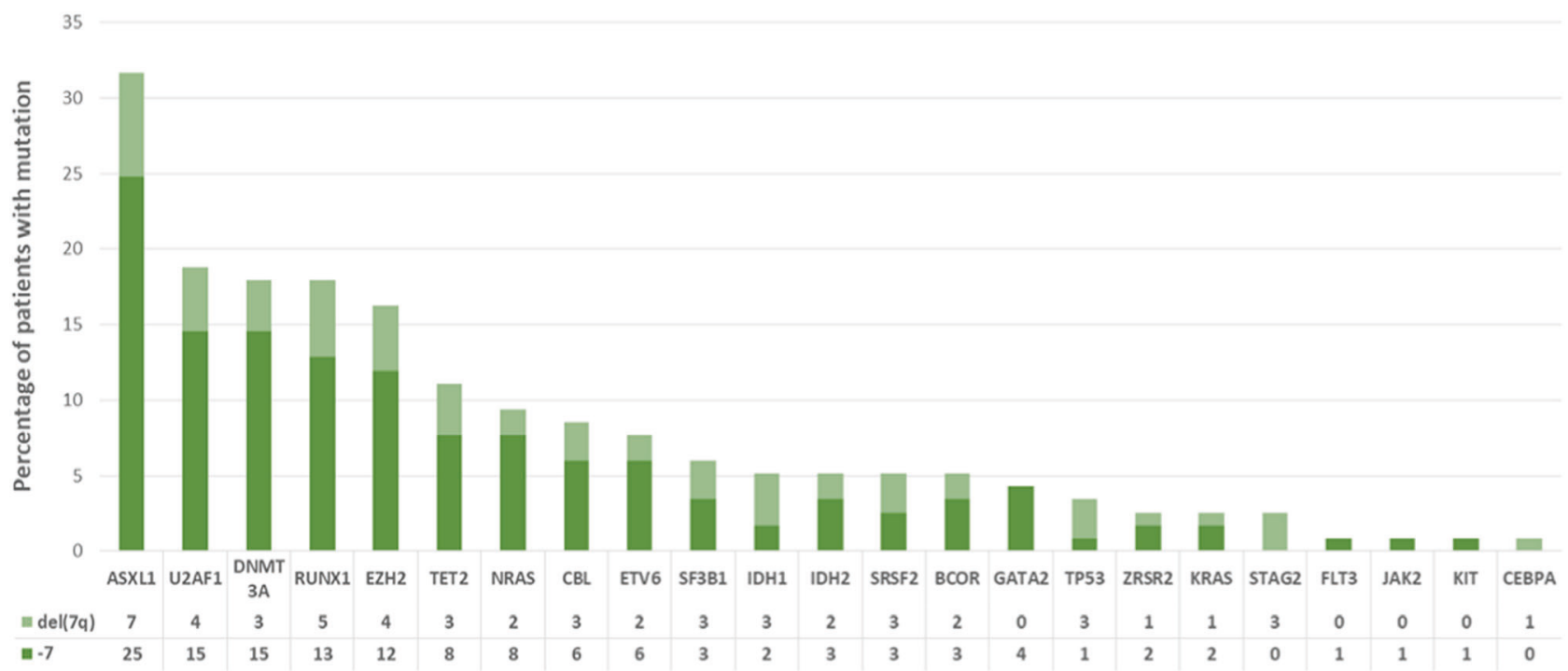

Fig. 3 Mutation frequency in the whole population and within -7 and $\operatorname{del}(7 q)$ patients.
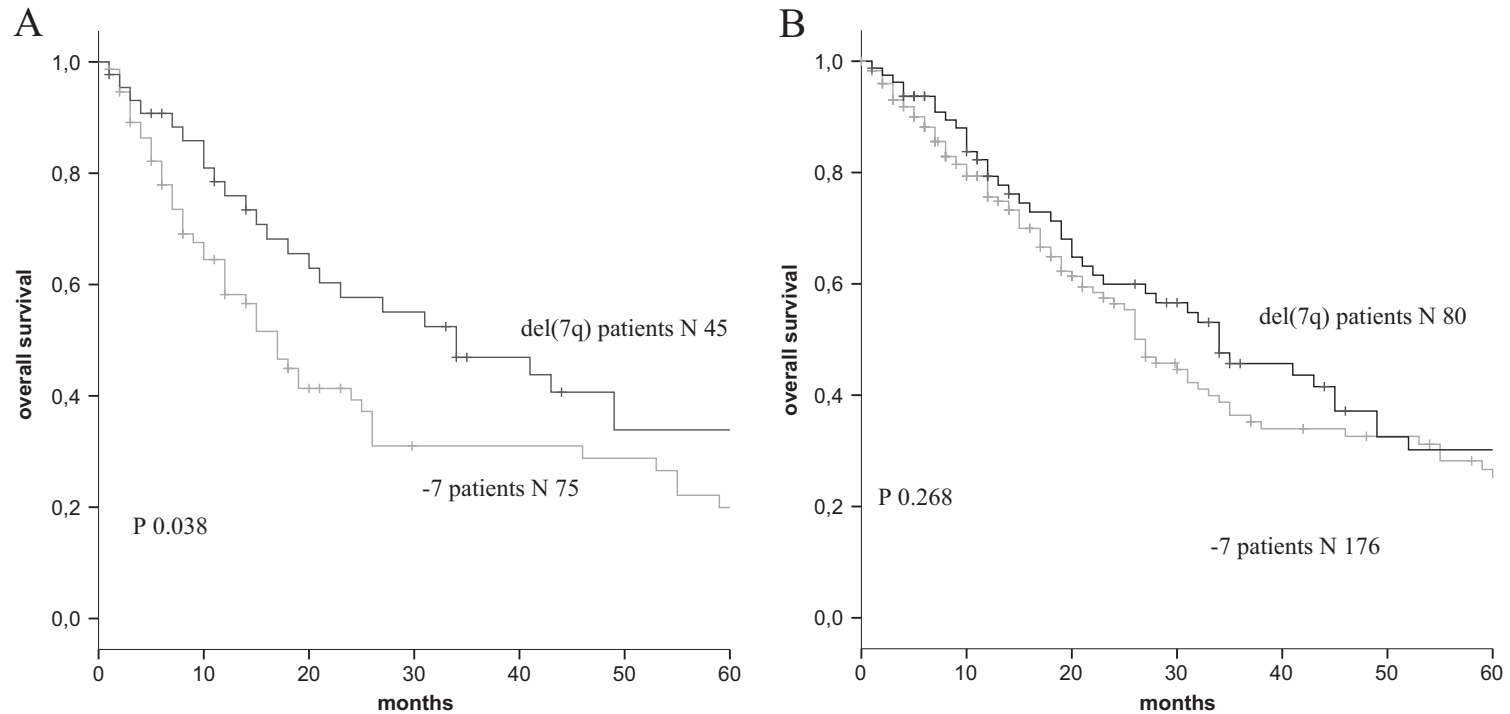

Fig. 4 Overall survival according to chromosome 7 abnormality. a Untreated patients: isolated -7 (median 17 months) vs del(7q) (median 34 months). b All patients -7 (median 27 months) vs del(7q) (median 34 months).

mutations and worse outcome was confirmed $(\mathrm{p}=0.017)$. The lack of statistical significance of the impact of singlegene mutations was probably due to low patient number in each subcategory.

On multivariable analysis, the number of mutations of any of the genes in the panel was confirmed as an independent prognostic factor for OS together with percentage of BM blasts and presence of TP53 mutations, whereas del (7q)/-7 were not (Table 2).

We also analyzed separately the impact of single-gene mutation in $\operatorname{del}(7 q)$ patients and -7 patients, but due to a small number of mutations in each cytogenetic subgroup and coexistence of multiple mutations, the results were not conclusive and additionally did not allow multivariable analysis (see Supplementary results for more information).

We were able to correlate the response rate to therapy and the presence of mutations in only 62 patients. However, in patients treated first-line either with IC $(n=14)$ or AZA $(n=39)$, there was a superior response rate (complete response, partial response and haematological improvement) in those without mutations than in patients with mutations, $100 \%$ vs 29 and $100 \%$ vs $43 \%$, respectively. By contrast, no difference in response to immunosuppressive treatment $(n=9)$ was observed according to mutations (Supplementary data Table 3). 


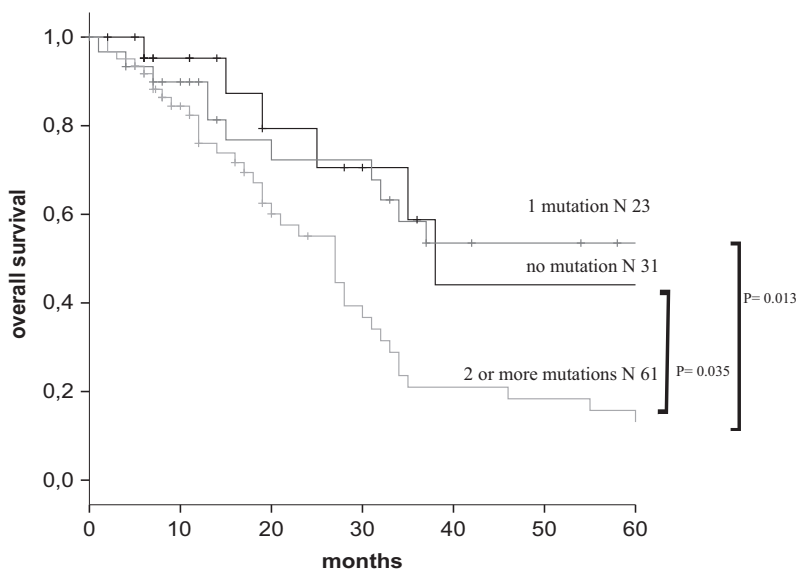

Fig. 5 Overall survival by mutation number: no mutation (median 38 months), one mutation (median 65 months) and two or more mutations (median 27 months).

Finally, there was no difference in OS according to the presence of somatic mutations at diagnosis in patients who underwent allo-HSCT $(P=0.470)$.

\section{AML transformation}

There was no difference in cumulative incidence of AML transformation between -7 and $\operatorname{del}(7 q)$ patients. Cumulative incidence of AML at 24 and 60 months was 28 and $35 \%$ in the -7 group and 22 and $38 \%$ in the del(7q) group, respectively $(P=0.866)$. However, AML cumulative incidence rates at 2 and 5 years were significantly higher in patients with $\geq 2$ mutations than in patients with 1 or no mutation (38\% vs $20 \%$ at 2 years and $49 \%$ vs $25 \%$ at 5 years, respectively, $P=0.044$, Fig. 6).

At AML progression, 6 of 39 patients in whom karyotype was available displayed a complex karyotype; the other 33 maintained an isolated $-7 /$ del (7q).

\section{Discussion}

In the largest series to date of patients with MDS or related myeloid neoplasms carrying isolated chromosome 7 abnormalities, we were able to show the relevant and independent role of the number of somatic mutations and of specific gene mutations in response to therapy and longterm outcomes.

Of note, our cohort of patients showed a younger age (median 65 years, confirmed also excluding MDS/MPN patients) than expected in MDS and largely comprised treated patients $(52 \%)$. Interestingly, in contrast to the results by Cordoba et al. [7] that showed a higher percentage of patients with high-risk disease in the -7 cohort, $48 \%$ of the patients in the -7 group had a lower-risk disease with less than $5 \%$ of blasts in BM, similar to the $\operatorname{del}(7 \mathrm{q})$ group. Moreover, apart from platelet count, we could not find any other difference in disease characteristics across the two groups, including frequency and distribution of somatic mutations.

In line with the findings reported in other studies [7$9,35]$, untreated patients with isolated del(7q) had a better outcome than patients with -7 . However, this difference was strongly attenuated in treated patients. This may suggest that the two different chromosomal abnormalities do not confer a different sensitivity to treatment or therapy, possibly improving outcomes in -7 compared with $\operatorname{del}(7 q)$.

Patients who harboured one or more mutation were older than wild-type patients. It is universally accepted that aging favours mutation development [36] and accumulation of mutations may occur stepwise, possibly over quite a long time. However, in multivariable analysis the number of mutations was a predictor of OS independently of patients' age.

In this study, we also observed a higher percentage of somatic mutations in genes involved in methylation and chromatin modifications than expected in MDS patients $[33,34]$. These data might explain the previously described greater sensitivity of -7 patients to AZA treatment [37]. By contrast, there were fewer TET2-mutated patients, probably due to younger age, and also a lower number of SF3B1mutated patients, as only few patients had MDS with ring sideroblasts.

Furthermore, there was also a high frequency of mutations in genes associated with adverse prognosis in previous studies, in particular ASXL1, DNMT3A, RUNX1, U2AF, NRAS and ETV6 [31, 32], whereas the incidence of mutations in TP53 was low. Indeed, harbouring a mutation of either one of the splicing factors or TP53 or NRAS had an adverse and independent effect on OS, and this poor outcome was also seen in patients with $\geq 2$ mutations in any of the examined genes, as previously shown in other studies $[33,38]$.

It has been shown that somatic mutations that detected pre-allo-HCT may affect OS after transplant [39, 40]. In our study, no difference in OS according to mutation at diagnosis in the subset of transplanted patients was observed. However, mutational status immediately prior to transplant was not available, and the effect of mutations may have been confounded by other variables, especially treatment pre-allo-HCT.

This series also confirmed that the partial loss of chromosome 7 has a more favourable effect on outcomes than the total loss, especially in untreated patients. However, the somatic gene mutational pattern blurred the impact on OS by the two chromosome 7 cytogenetic subgroups. Importantly, in patients treated both with AZA and IC, the 
Table 2 Multivariable analysis.

\begin{tabular}{lllrl}
\hline Multivariate analysis & & & & \\
\hline Variable & HR & $95.0 \%$ CI for $\operatorname{Exp}(\mathrm{B})$ & $P$ value & \\
\hline BM blast $>10 \%$ vs $<10 \%$ & 3.332 & 1.511 & 7.343 & 0.011 \\
TP53 mutation yes vs no & 5.739 & 1.709 & 19.267 & 0.005 \\
Mutation number $\geq 2$ vs $<2$ & 2.071 & 1.140 & 3.759 & 0.017 \\
\hline
\end{tabular}

Prognostic factors for survival on multivariable analysis. Variables included in the model were age, del(7q) or -7 , BM blast percentage, BM cellularity, transfusion dependency, number of mutations and TP53 status; only significant variables are shown.

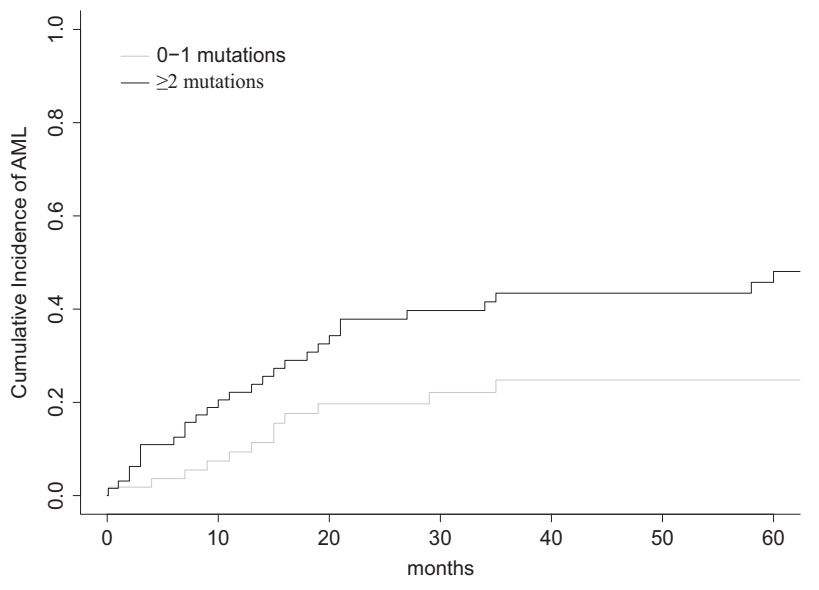

Fig. 6 Cumulative incidence (CI) of AML and death by mutation number. No or 1 mutation (CI at 2 years $20 \%$, at 5 years $25 \%$ ) vs $\geq 2$ mutations (CI at 2 years $38 \%$, at 5 years $40 \%$ ), $P=0.044$.

presence of somatic mutations impacted OS whereas the cytogenetic subgroup did not. This may suggest that the chemosensitivity of the MDS clone correlates more with the mutational pattern than with the type of chromosome 7 abnormalities.

In summary, the data suggest that indeed there is a difference in OS between -7 and $\operatorname{del}(7 \mathrm{q})$, but more importantly blast cell percentage and the number and type of mutations are more relevant in terms of prognosis, and possibly, response to therapy.

This study adds further evidence to the emerging data demonstrating the added value of somatic mutations on risk stratification and therapeutic decisions in MDS and AML [31, 33, 41], possibly improving the one achieved by cytogenetic abnormalities alone. Whether NGS results should be currently included in clinical routine practice is still debatable [42]. Undoubtedly, as they add relevant prognostic information, the standardisation of performing and reporting NGS techniques before their universal use must be considered as a high priority.

Funding This work was supported in part by a grant from the Instituto de Salud Carlos III, Ministerio de Economia y Competividad, Spain (PI/14/00013; PI/17/0575); 2017 SGR288 (GRC) Generalitat de Catalunya; economical support from CERCA Programme/Generalitat de Catalunya, Fundació Internacional Josep Carreras and from Celgene
International. The research leading to this invention has received funding from 'la Caixa' Foundation.

Author contributions GJM designed the study and provided funding for the research; EC and AGK performed the research and the statistical analysis; EC and AGK collected data, analyzed data and wrote the paper; EC, AGK, VA, ES, JS, DH, SB, SAM, AK, JC, NL, DF, UG, ABVM, GFS, FS, GJM and VS collected data and treated patients; KS and $\mathrm{BH}$ performed the cytogenetic analysis; SB, SAM, NL and AK contributed to the study experiments; DH, VS, GFS, FS and GJM commented on the paper; all the authors reviewed and approved the paper.

\section{Compliance with ethical standards}

Conflict of interest EC, AGK, VA, ES, JS, DH, KS, SB, SAM, AK, JC, NL, DF, UG, BH, ABVM, FS and GJM have no conflict of interests; VS has received honoraria from honoraria da Celgene, Novartis, Takeda, Amgen, Astex and Janssen; GFS has received honoraria from and/or played an advisory role for AbbVie, Amgen, Böehringer-Ingelheim, Celgene, Helsinn Healthcare and HoffmannLa Roche, Janssen-Cilag and Novartis. GFS and ES work at Hospital Universitario y Politécnico $\mathrm{La} \mathrm{Fe}$, which receives research funding and/or participates in multiple clinical trials funded by different pharmaceutical companies, including AbbVie, Amgen, BöehringerIngelheim, Bristol-Myers Squibb, Celgene, Helsinn Healthcare and Hoffman - La Roche, Janssen-Cilag, Novartis and Onconova. GFS is also a member of the Spanish Group on Myelodysplastic Syndromes (Grupo Español de Síndromes Mielodisplásicos, GESMD), which is sponsored by Celgene and Novartis.

Publisher's note Springer Nature remains neutral with regard to jurisdictional claims in published maps and institutional affiliations.

\section{References}

1. Fenaux P, Morel P, Lai JL. Cytogenetics of myelodysplastic syndromes. Semin Hematol. 1996;33:127-38. http://www.ncbi. nlm.nih.gov/pubmed/8722683.

2. Morel P, Declercq C, Hebbar M, Bauters F, Fenaux P. Prognostic factors in myelodysplastic syndromes: critical analysis of the impact of age and gender and failure to identify a very-low-risk group using standard mortality ratio techniques. Br J Haematol. 1996;94:116-9. http://www.ncbi.nlm.nih.gov/pubmed/8757518.

3. Pasquali F, Bernasconi P, Casalone R, Fraccaro M, Bernasconi C, Lazzarino M, et al. Pathogenetic significance of "pure" monosomy 7 in myeloproliferative disorders. Analysis of 14 cases. Hum Genet. 1982;62:40-51. http://www.ncbi.nlm.nih.gov/pubmed/ 6961098.

4. Bernasconi P, Alessandrino EP, Boni M, Bonfichi M, Morra E, Lazzarino $\mathrm{M}$, et al. Karyotype in myelodysplastic syndromes: 
relations to morphology, clinical evolution, and survival. Am J Hematol. 1994;46:270-7. http://www.ncbi.nlm.nih.gov/pubmed/ 8037176.

5. Velloso ER, Michaux L, Ferrant A, Hernandez JM, Meeus P, Dierlamm J. et al. Deletions of the long arm of chromosome 7 in myeloid disorders: loss of band 7q32 implies worst prognosis. Br J Haematol.1996;92:574-81. http://www.ncbi.nlm.nih.gov/pubmed/ 8616020.

6. Greenberg P, Cox C, LeBeau MM, Fenaux P, Morel P, Sanz G, et al. International scoring system for evaluating prognosis in myelodysplastic syndromes. Blood. 1997;89:2079-88. http://www. ncbi.nlm.nih.gov/pubmed/9058730.

7. Cordoba I, González-Porras JR, Nomdedeu B, Luño E, de Paz R, Such E, et al. Better prognosis for patients with $\operatorname{del}(7 q)$ than for patients with monosomy 7 in myelodysplastic syndrome. Cancer. 2012;118:127-33. http://www.ncbi.nlm.nih.gov/pubmed/21717439.

8. Schanz J, Tüchler H, Solé F, Mallo M, Luño E, Cervera J, et al. New comprehensive cytogenetic scoring system for primary myelodysplastic syndromes (MDS) and oligoblastic acute myeloid leukemia after MDS derived from an international database merge. J Clin Oncol. 2012;30:820-9. http://jco.ascopubs.org.offca mpus.dam.unito.it/content/30/8/820.full.

9. Pozdnyakova O, Miron PM, Tang G, Walter O, Raza A, Woda B, et al. Cytogenetic abnormalities in a series of 1,029 patients with primary myelodysplastic syndromes: a report from the US with a focus on some undefined single chromosomal abnormalities. Cancer. 2008;113:3331-40. http://www.ncbi.nlm.nih.gov/pubmed/ 18988232.

10. Jerez A, Sugimoto Y, Makishima H, Verma A, Jankowska AM, Przychodzen B, et al. Loss of heterozygosity in $7 \mathrm{q}$ myeloid disorders: clinical associations and genomic pathogenesis. Blood. 2012;119:6109-17. http://www.pubmedcentral.nih.gov/articlerender. fcgi?artid $=3383019 \&$ tool $=$ pmcentrez\&rendertype $=$ abstract.

11. Greenberg PL, Tuechler H, Schanz J, Sanz G, Garcia-Manero G, Solé F, et al. Revised international prognostic scoring system for myelodysplastic syndromes. Blood. 2012;120:2454-65. http:// bloodjournal.hematologylibrary.org.offcampus.dam.unito.it/content/ 120/12/2454.long.

12. Döhner K, Brown J, Hehmann U, Hetzel C, Stewart J, Lowther G, et al. Molecular cytogenetic characterization of a critical region in bands 7q35-q36 commonly deleted in malignant myeloid disorders. Blood. 1998;92:4031-5. http://www.ncbi.nlm.nih.gov/ pubmed/9834205.

13. Le Beau MM, Espinosa R, Davis EM, Eisenbart JD, Larson RA, Green ED. Cytogenetic and molecular delineation of a region of chromosome 7 commonly deleted in malignant myeloid diseases. Blood. 1996;88:1930-5. http://www.ncbi.nlm.nih.gov/pubmed/ 8822909.

14. Asou H, Matsui H, Ozaki Y, Nagamachi A, Nakamura M, Aki D, et al. Identification of a common microdeletion cluster in 7q21.3 subband among patients with myeloid leukemia and myelodysplastic syndrome. Biochem Biophys Res Commun. 2009;383:245-51. http://www.ncbi.nlm.nih.gov/pubmed/19358830.

15. Ernst T, Chase AJ, Score J, Hidalgo-Curtis CE, Bryant C, Jones $\mathrm{AV}$, et al. Inactivating mutations of the histone methyltransferase gene EZH2 in myeloid disorders. Nat Genet. 2010;42:722-6. http://www.ncbi.nlm.nih.gov/pubmed/20601953.

16. Makishima H, Jankowska AM, Tiu RV, Szpurka H, Sugimoto Y, Hu $\mathrm{Z}$, et al. Novel homo- and hemizygous mutations in EZH2 in myeloid malignancies. Leukemia. 2010;24:1799-804. http://www.nature.com. offcampus.dam.unito.it/leu/journal/v24/n10/full/leu2010167a.html.

17. Nikoloski G, Langemeijer SMC, Kuiper RP, Knops R, Massop M, Tönnissen ERLTM, et al. Somatic mutations of the histone methyltransferase gene EZH2 in myelodysplastic syndromes. Nat Genet. 2010;42:665-7. http://www.ncbi.nlm.nih.gov/pubmed/ 20601954.
18. Nagamachi A, Matsui H, Asou H, Ozaki Y, Aki D, Kanai A, et al. Haploinsufficiency of SAMD9L, an endosome fusion facilitator, causes myeloid malignancies in mice mimicking human diseases with monosomy 7. Cancer Cell. 2013;24:305-17. http://www. ncbi.nlm.nih.gov/pubmed/24029230.

19. Chen C, Liu Y, Rappaport AR, Kitzing T, Schultz N, Zhao Z, et al. MLL3 is a haploinsufficient $7 \mathrm{q}$ tumor suppressor in acute myeloid leukemia. Cancer Cell. 2014;25:652-65. http://www. ncbi.nlm.nih.gov/pubmed/24794707.

20. Zhou L, Opalinska J, Sohal D, Yu Y, Mo Y, Bhagat T, et al. Aberrant epigenetic and genetic marks are seen in myelodysplastic leukocytes and reveal Dock4 as a candidate pathogenic gene on chromosome 7q. J Biol Chem. 2011;286:25211-23. http://www. ncbi.nlm.nih.gov/pubmed/21532034.

21. Inaba $\mathrm{T}$, Honda $\mathrm{H}$, Matsui $\mathrm{H}$. The enigma of monosomy 7 . Blood. 2018;131:2891-8. http://www.ncbi.nlm.nih.gov/pubmed/29615405.

22. Hosono N, Makishima H, Jerez A, Yoshida K, Przychodzen B, McMahon S, et al. Recurrent genetic defects on chromosome $7 \mathrm{q}$ in myeloid neoplasms. Leukemia. 2014;28:1348-51. http://www. ncbi.nlm.nih.gov/pubmed/24429498.

23. Wong JCY, Zhang Y, Lieuw KH, Tran MT, Forgo E, Weinfurtner $\mathrm{K}$, et al. Use of chromosome engineering to model a segmental deletion of chromosome band $7 \mathrm{q} 22$ found in myeloid malignancies. Blood. 2010;115:4524-32. http://www.ncbi.nlm.nih.gov/ pubmed/20233966.

24. Vardiman JW, Thiele J, Arber DA, Brunning RD, Borowitz MJ, Porwit A, et al. The 2008 revision of the World Health Organization (WHO) classification of myeloid neoplasms and acute leukemia: rationale and important changes. Blood. 2009;114:937-51. http://bloodjournal.hematologylibrary.org/ content/114/5/937.full.

25. Thiele J, Kvasnicka HM, Facchetti F, Franco V, van der Walt J, Orazi A. European consensus on grading bone marrow fibrosis and assessment of cellularity. Haematologica. 2005;90:1128-32. http://www.ncbi.nlm.nih.gov/pubmed/16079113.

26. Bono E, McLornan D, Travaglino E, Gandhi S, Gallì A, Khan AA, et al. Clinical, histopathological and molecular characterization of hypoplastic myelodysplastic syndrome. Leukemia. 2019;33: 2495-505. http://www.ncbi.nlm.nih.gov/pubmed/30940907.

27. Cheson BD, Greenberg PL, Bennett JM, Lowenberg B, Wijermans PW, Nimer SD, et al. Clinical application and proposal for modification of the International Working Group (IWG) response criteria in myelodysplasia. Blood. 2006;108:419-25.

28. Mian SA, Smith AE, Kulasekararaj AG, Kizilors A, Mohamedali $\mathrm{AM}$, Lea NC, et al. Spliceosome mutations exhibit specific associations with epigenetic modifiers and proto-oncogenes mutated in myelodysplastic syndrome. Haematologica. 2013;98:1058-1066. http://www.haematologica.org/content/98/7/ 1058.long.

29. Marisavljevic D, Cemerikic V, Rolovic Z, Boskovic D, Colovic M. Hypocellular myelodysplastic syndromes: clinical and biological significance. Med Oncol. 2005;22:169-75. http://www.ncbi. nlm.nih.gov/pubmed/15965280.

30. Huang T-C, Ko B-S, Tang J-L, Hsu C, Chen C-Y, Tsay W, et al. Comparison of hypoplastic myelodysplastic syndrome (MDS) with normo-/hypercellular MDS by International Prognostic Scoring System, cytogenetic and genetic studies. Leukemia. 2008;22:544-50. http://www.ncbi.nlm.nih.gov/pubmed/18094713.

31. Bejar R, Stevenson K, Abdel-Wahab O, Galili N, Nilsson B, Garcia-Manero $\mathrm{G}$, et al. Clinical effect of point mutations in myelodysplastic syndromes. N Engl J Med. 2011;364:2496-506. https://doi.org/10.1056/NEJMoa1013343.

32. Jung S-H, Kim Y-J, Yim S-H, Kim H-J, Kwon Y-R, Hur E-H, et al. Somatic mutations predict outcomes of hypomethylating therapy in patients with myelodysplastic syndrome. Oncotarget. 2016;7: 55264-75. http://www.ncbi.nlm.nih.gov/pubmed/27419369. 
33. Papaemmanuil E, Gerstung M, Malcovati L, Tauro S, Gundem G, Van Loo P, et al. Clinical and biological implications of driver mutations in myelodysplastic syndromes. Blood. 2013;122: 3616-27. http://bloodjournal.hematologylibrary.org/content/122/ 22/3616.long?sso-checked $=1$.quiz3699.

34. Haferlach T, Nagata Y, Grossmann V, Okuno Y, Bacher U, Nagae $\mathrm{G}$, et al. Landscape of genetic lesions in 944 patients with myelodysplastic syndromes. Leukemia. 2014;28:241-7. http://www. ncbi.nlm.nih.gov/pubmed/24220272.

35. Bernasconi P, Klersy C, Boni M, Cavigliano PM, Calatroni S, Giardini I, et al. Incidence and prognostic significance of karyotype abnormalities in de novo primary myelodysplastic syndromes: a study on 331 patients from a single institution. Leukemia. 2005;19:1424-31. http://www.nature.com.offcampus. dam.unito.it/leu/journal/v19/n8/full/2403806a.html.

36. Xie M, Lu C, Wang J, McLellan MD, Johnson KJ, Wendl MC, et al. Age-related mutations associated with clonal hematopoietic expansion and malignancies. Nat Med. 2014;20:1472-8.

37. Fenaux P, Mufti GJ, Hellström-Lindberg E, Santini V, Gattermann N, Germing U, et al. Azacitidine prolongs overall survival compared with conventional care regimens in elderly patients with low bone marrow blast count acute myeloid leukemia. J Clin Oncol. 2010;28:562-9. http://jco.ascopubs.org.offcampus.dam. unito.it/content/28/4/562.full.
38. Montalban-Bravo G, Takahashi K, Patel K, Wang F, Xingzhi S, Nogueras GM, et al. Impact of the number of mutations in survival and response outcomes to hypomethylating agents in patients with myelodysplastic syndromes or myelodysplastic/ myeloproliferative neoplasms. Oncotarget. 2018;9:9714-27. http://www.oncotarget.com/fulltext/23882.

39. Della Porta MG, Malcovati L, Boveri E, Travaglino E, Pietra D, Pascutto $\mathrm{C}$, et al. Clinical relevance of bone marrow fibrosis and CD34-positive cell clusters in primary myelodysplastic syndromes. J Clin Oncol. 2009;27:754-62. http://jco.ascopubs.org/ content $/ 27 / 5 / 754$.abstract?ijkey $=\mathrm{b} 1 \mathrm{fbbc} 2 \mathrm{~d} 4 \mathrm{~d} 064656 \mathrm{~b} 27 \mathrm{~b} 5 \mathrm{da} 1 \mathrm{a}$ 506032a8fa0e190\&keytype2=tf_ipsecsha.

40. Lindsley RC, Saber W, Mar BG, Redd R, Wang T, Haagenson $\mathrm{MD}$, et al. Prognostic mutations in myelodysplastic syndrome after stem-cell transplantation. N Engl J Med. 2017;376:536-47. https://doi.org/10.1056/NEJMoa1611604.

41. Cazzola M, Della Porta MG, Malcovati L. The genetic basis of myelodysplasia and its clinical relevance. Blood. 2013;122: 4021-34. http://bloodjournal.hematologylibrary.org/content/122/ 25/4021.full.

42. Steensma DP. How I use molecular genetic tests to evaluate patients who have or may have myelodysplastic syndromes. Blood. 2018;132:1657-63. http://www.bloodjournal.org/content/ 132/22/2419.2.long?sso-checked=true.

\section{Affiliations}

\section{Elena Crisà $\mathbb{D}^{1,2,3}$ - Austin G. Kulasekararaj ${ }^{1}$ - Vera Adema ${ }^{4,5}$ - Esperanza Such ${ }^{6,7}$ - Julie Schanz ${ }^{8}$ - Detlef Haase ${ }^{8}$. Katayoon Shirneshan ${ }^{8} \cdot$ Steven Best ${ }^{9} \cdot$ Syed A Mian ${ }^{1,10}$ - Aytug Kizilors ${ }^{9} \cdot$ José Cervera $^{11} \cdot$ Nicholas Lea $^{9}$. Dario Ferrero $^{3,12}$. Ulrich Germing ${ }^{13}$ - Barbara Hildebrandt ${ }^{14}$. Ana Belén Valencia Martínez ${ }^{15}$ - Valeria Santini ${ }^{3,15}$. Guillermo F. Sanz $\mathbb{D i}^{6,7,16}$. Francesc Solé ${ }^{4}$. Ghulam J. Mufti ${ }^{1}$}

1 Department of Haematological Medicine, King's College Hospital, NHS Foundation Trust, London, UK

2 Division of Hematology, Department of Translational Medicine, University of Eastern Piedmont, Novara, Italy

3 Fondazione Italiana Sindromi Mielodisplastiche (FISiM), Bologna, Italy

4 Institut de Recerca Contra la Leucèmia Josep Carreras, ICOHospital Germans Trias i Pujol, Universitat Autònoma de Barcelona, Barcelona, Spain

5 Department of Translational Hematology and Oncology Research, Taussig Cancer Institute, Cleveland Clinic, Cleveland, $\mathrm{OH}$, USA

6 Department of Hematology, Hospital Universitario La Fe, Valencia, Spain

7 Centro de Investigación Biomédica en Red de Cáncer (CIBERONC), Instituto de Salud Carlos III, Madrid, Spain
8 Department of Hematology and Medical Oncology, University Medical Center of Göttingen, Göttingen, Germany

9 Laboratory for Molecular Haemato-Oncology, King's College Hospital, NHS Foundation Trust, London, UK

10 Haematopoietic Stem Cell Laboratory, The Francis Crick Institute, London, UK

11 Genetics Unit, Hospital Universitario La Fe, Valencia, Spain

12 Division of Hematology, University of Torino, AOU Città della Salute e della Scienza, Torino, Italy

13 Department of Hematology, Oncology, and Clinical Immunology, Heinrich-Heine-University Düsseldorf, Düsseldorf, Germany

14 Institute of Human Genetics, Heinrich-Heine-University Düsseldorf, Düsseldorf, Germany

15 MDS UNIT, AOU Careggi, University of Florence, Firenze, Italy

16 Department of Medicine, University of Valencia, Valencia, Spain 